\title{
REPORT
}

\section{Highland Lake Workshop \\ Conversations about Critical Action}

\author{
Donna Riley, ${ }^{*}$ Nasser Saleh, ${ }^{\dagger}$ Darko Matovic, ${ }^{\ddagger}$ and Caroline Baillie ${ }^{\S}$
}

* Department of Engineering Education, Virginia Polytechnic and State University, dmriley@vt.edu

† Engineering \& Science Library, Queen's University, nasser.saleh@queensu.ca

‡ Department of Mechanical and Materials Engineering, Queen's University, darko@me.queensu.ca

$\S$ Faculty of Engineering, Mathematics and Computing, University of Western Australia, caroline.baillie@uwa.edu.au

On December 6, 2014, Engineering, Social Justice, and Peace (ESIP) co-hosted a one-day workshop with Critical Stage and the University of Western Australia titled "Conversations about Critical Action." The workshop was hosted at the North American Cultural Lab in Highland Lake, New York. An interdisciplinary group of 14 participants from Australia, England, Canada, and the United States met, representing academics, artists, actors, directors, film-makers, activists, teachers and engineers whose common interest is in making a difference both individually and as a community.

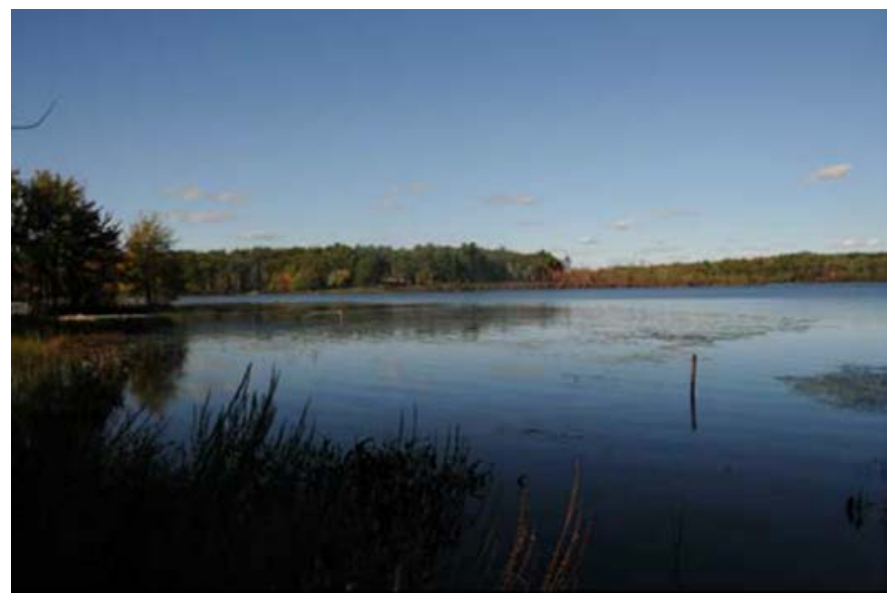

Highland Lake

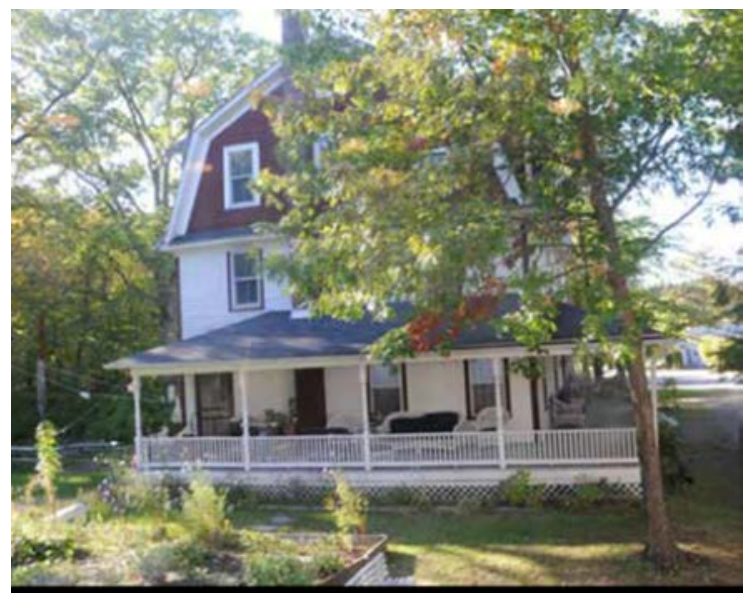

LakeWood House

Images from http://www.nacl.org

The conversation focused on critical reflections of past, present and future actions with the goal of enhancing social justice in discussing the workshop's main theme: How might I be the person I would most like to be and contribute to making the world more socially just?

Using an Open Space Technology format and Talking Circle processes with an interactive approach, the workshop participants developed self-organized sessions. 
The participants identified the following topics to answer the workshop's main question:

1) How to unlearn/transcend our internal(ized) ideological frameworks in order to become capable of true change

2) The power of language and cultural difference: What is your world? How is it shaped by geography, language, culture, geopolitics? How does that shape our struggles and work together?

3) The role of Poets and Poetry in the work of social justice and in the world

4) How to stay true to ourselves in professional lives that often do not share our values

5) Visioning a "new new school" based in social justice

Participants closed with a reflection on what they noticed and made declarations and offers for the work ahead.

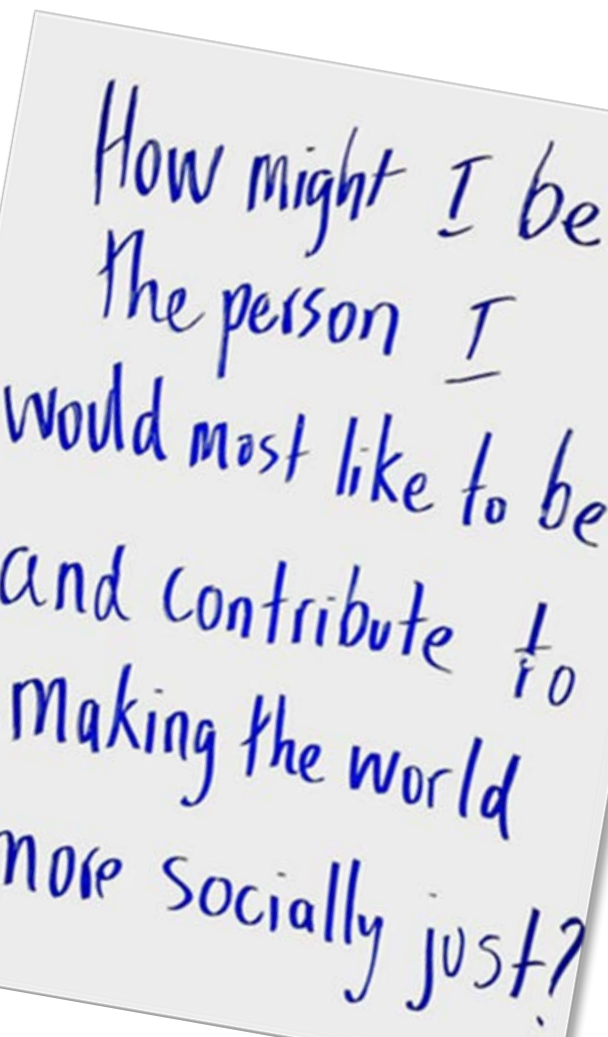

\section{UNLEARNING/TRANSCENDING IDEOLOGICAL FRAMEWORKS}

Many problems in the world are caused by ideologies with inadequate or biased value systems and ethical principles. As we grow up embedded in the existing value systems developed and perpetuated by the forces of privilege and injustice, we inevitably internalize their core premises. How and to what extent can we free ourselves and our worldview to become effective agents of change? Merely creating new ideologies and superior/humanist ethical structures is not enough if we remain co-opted and unable to unlearn these foundational biases. Or is it necessary to unlearn? For an ethical system agreed upon inside a room, amongst the like-minded participants, to meet and inspire wider community or to enact in the world, we need a robust shift at a foundational level (an example of the opposite process is described in Great Transformation by Karl Polanyi).

One participant suggested that we don't need to unlearn ideological frameworks, if this is even possible. Rather we can strive to transcend it. An analogy in math is that we first define objects (e.g. vectors) in certain coordinate systems, but later we transcend it to define these objects from any coordinate system. As we strive to reach new viewpoints we do that by becoming capable of seeing the world, communities, and people from multiple angles. Another analogy: we can define a colour in terms of primary colours and hue, but it is not how the brain processes them. It is capable of dynamically interacting in "nature coordinates."

Through these and other analogies participants reached a consensus that we don't need to unlearn the internalized patterns, but rather to transcend them through an interplay of empathy, learning through listening and through deeper identification with other complementary points of view. Ideally, one should reach the point where she or he sees the issues of social justice with clarity, not by replacing one set of lenses with another, but by becoming capable of transcending any original starting point. In a way, the nature of connections and interaction between the workshop participants illustrated by example how people coming from different backgrounds can share a commonly minted viewpoint on the interplay of engineering and social justice. On the other hand, 
the participants also recognised that the group makeup lacked broader racial diversity and that they predominantly are associated with academic life. The desire and challenge to expand along both of these axes was voiced during the wrap-up session.

\section{Poetry AND the Role of Poets IN THe World}

The group talked about the ways in which poetry can help us recognize ourselves in others' experiences, and help us rediscover parts of ourselves lost to process of social conformity and injustice. It can remind us of who we are meant to be, who we want to be, and who we can be. Poetry is life-affirming and provides inspiration for our work.

We can find our inner child. Children respond to poetry, and write poetry without adult inhibitions. While many of us have had the experience of spirited and colorful childhoods, we have also seen some of this fade away or be pushed out of us through schooling, or parents, or other forces.

As an adult, Mary Ann Evans, more popularly known as George Eliot, considered the plight of women locked into their adult bonds. The novel Mill on the Floss, which she wrote in 1860, relates the story of the protagonist Maggie at different stages of her life. We discussed the literary portrayal of the child locked inside the adult, particularly due to the gendered nature of freedom of spirit of the day and how this portrayal allowed us to remember our own childhood spirits-those force fields which know no bounds.

Poets bare their souls to the world. It is likely that Shelley and other romantic poets would be told today that they "feel too much" as some of us who care about social justice and peace are told. But in poetry we gain courage in the present moment, and we are sustained by ideas immortalized on the page, which travel through time.

\section{The Power of Language and Cultural Difference}

\section{What is your world? How is it shaped by geography, language, culture, geopolitics? How does that shape our struggles and work together?}

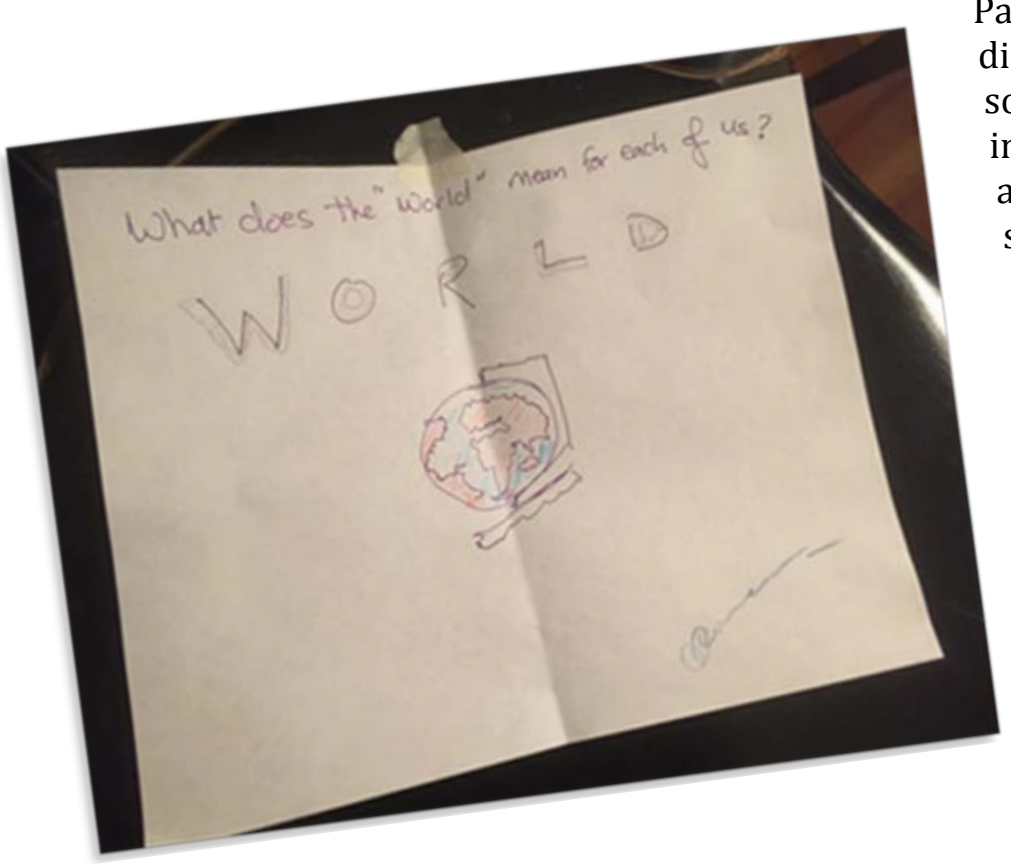

Participants discussed the effect of awareness of different languages as an enabler to understanding social justice. The discussion extended from the intended meaning of words in different languages and that languages could be a barrier in certain situations. The discussion about "my world" focused on how each one of us can have her or his own world and how we are all affected with what has been already learned. A participant gave the example of the world map we grew up with in school and how this world map can be seen differently through different views/lenses. One participant shared the Ann Sexton poem Housewife, the first line of which is "some women marry houses," revealing an astute critique of a single word and its implications of how women's roles are defined and maintained. 
Another participant followed up with this topic and how she has experienced it in co-teaching a course in social justice with another instructor. "We were two very different personalities but with very similar sociocultural backgrounds. We were able to develop the concept of having the same frame but looking through different lenses; this helped us to teach students how to develop their own viewpoint based on this concept of frame and lenses." The concept of injustice was also discussed and how an enhanced experience of injustice has led some people to be proponent of open source movement. Examples of injustice in different worlds were represented in a way that there is need to experience injustice or to have example of injustice explained in order to understand justice.

\section{How to Stay True to Ourselves in Professional lives that Often Do Not SHARE OUR VALUES}

\section{How do we build supportive community that can sustain us in our work?}

How do we make time for what really matters? One participant shared how a friend recently asked her to reflect on why she says "yes" to different projects in her life. Some are undertaken out of obligation, some out of guilt, and others out of passion. We talked about how we can increase the number of projects and the amount of time spent on our passions and less time on our obligations, and still less time on things we do out of guilt. Is it possible to see guilt as the flip side of passion? To what extent can we mold our obligations to incorporate our passions? Many of us have chosen to stay in our particular professions (most in academia), but at what cost?

Another participant shared advice they received to "work a little, rest a little, last longer." In other words we need to take time out to avoid burnout. How do we schedule in our "ease time" and take it as seriously as other obligations and demands? One person shared how she struggled to maintain a rigid discipline of meditation in an eastern tradition but found that brushing the dog was itself meditative and created the space for her to work meditation and mindfulness practice into her everyday life.

What can we do to draw others to us? We talked about our strong sense of loneliness, how even when we reach out to allies in other fields, we sometimes feel alienated by a lack of common language or experience. Asking for help from colleagues can be powerful in building relationships with allies. It can help us name questions and find new language that helps us see our work in a new way. It can be energizing to find community in this kind of emergent action. In engineering education, with its history of military structure and links to our present economic systems, it can be transformative in itself to go about doing things this way.

At the same time the extra work we do to fit in can sometimes be exhausting. Sometimes our allies can betray us, and this can hurt more than the expected volleys from known enemies. We talked about finding the balance between protecting our hearts and letting ourselves be heartbroken. Sometimes we need to focus on tangible, achievable actions that are local and small scale, where we see a difference, no matter how small. Other times we can act with the sure knowledge that:

"It is from numberless, diverse acts of courage and belief that human history is shaped. Each time a [person] takes a stand for an ideal, or acts to improve the lots of others, or strikes out against injustice, [that person] sends forth a tiny ripple of hope. And crossing each other from a million different centers of energy and daring, those ripples build a current that can sweep down the mightiest walls of oppression and resistance" (Robert Kennedy, University of Capetown, 1966) 
We talked about where we find a sense of community-the people to whom we do not need to explain ourselves. One of us finds this on a women's hockey team. And many of us felt it in the space of the Highland Lake retreat. We agreed as a group to commit to create a Google Hangout group that creates regular (monthly) space for "ease time" and reflection, and accountability for our collective quest to stay true to ourselves. As one participant noted, our very souls are at stake.

One participant spoke to the power of art and design to create space for different ways of being, thinking, and doing. This led to a discussion about how we make our offices a refuge and a place that invites community. Many of us surround ourselves at home and at work with living things, especially plants and animals, which help us be and become more of who we are or strive to be. Art, photography, poetry, meaningful quotes, student work, all contribute to creating a space that reminds us of who we want to be. We are circulating a book by Ursula Franklin, who is a role model for many of us. We talked about some items that have failed to invite but have instead alienated others, and discussed the risks and rewards of seeking to shape some of the shared spaces on our campus. While it can be meaningful to realize shared space belongs to us as well, and we can have a profound influence on students and coworkers, at the same time, it can be painful to negotiate shared space when others do not share our values.

\section{THE NEW NEW SCHOOL}

The question was posed as to whether it was possible to create an alternative school which both transformed society towards a more socially just one, and acknowledged the emotional and emancipatory learning needed for such an education. We agreed to focus on engineering as a profession as this would draw best from our own expertise. We discussed the potential forms of pedagogy, the styles of teaching and mentoring, the location, the framing and the purpose. Many ideas emerged and as a group we agreed to take this existing project forward for our own ESJP community but also with the intent of modelling for other professions. We committed to research existing alternative schools with similar aims, and to explore the necessary next steps to begin our New New School.

\section{FINAL THOUGHTS}

Participants were invited to reflect on issues discussed during the day. There was a great deal of gratitude expressed for the workshop facilitator, for the venue, for those who planned and those who participated, and for the time and space for reflection. One participant observed a pessimism regarding the ethical limitations of institutions (academic in particular, but also societal, governmental) in responding to critical social justice issues, and observed that this is countered by natural instincts for robust ethical structures that inform "new" educational spaces and actions. There is a ready synergy existing between people from very different cultural localities regarding these challenges. There was a recognition that pessimism and cynicism can impede our ability to act and build community. We began to brainstorm some steps for practical action in the months ahead, and participants make declarations and offers in this regard.

For example, two participants agreed to convene an online hangout time for anyone who would like to check in about their progress in staying true to ourselves in professional lives that often do not share our values, and in building supportive community that can sustain us in our work. Others committed to extend the work of the ESJP community in creative ways, including developing a structure for online course delivery of ESJP themed courses, offering workshops to further our work together, contributing to the journal IJESJP, and developing inroads with engineering practitioners. Others committed to help develop the new new school. Others committed to change 
their teaching practices in ways that reflect what they learned at the workshop, and to write about their course innovations in engineering, social justice, and peace.

Looking back at the workshop, an additional benefit to the participants has become clear: we learned a new, effective technique of creating the question space, discussion space and follow-up space for all participants. We also experienced the power of follow-up commitments, one of these being this review. While we didn't spell it out as a specific task during the wrap-up workshop session, we formed the plan immediately following the workshop as we were preparing to depart from Highland Lake. Several of us felt that this was a natural emergence, in tune with the spirit of Open Space Technology. We hope by sharing the experience of the workshop in the journal that others can join in reflection and action on these themes.

\section{ACKNOWLEDGMENT}

The authors wish to acknowledge and thank all workshop participants for their contributions. 